\title{
Seasonal depletion of resources intensifies trophic interactions in subarctic freshwater fish communities
}

\author{
BRIAN HAYDEN*,+, CHRIS HARROD ${ }^{*}$, ELONI SONNINEN" AND KIMMO K. KAHILAINEN $^{\dagger, \$}$ \\ *Biology Department, Canadian Rivers Institute, University of New Brunswick, Fredericton, NB, Canada \\ ${ }^{\dagger}$ Kilpisjärvi Biological Station, University of Helsinki, Helsinki, Finland \\ ¿Department of Environmental Sciences, University of Helsinki, Helsinki, Finland \\ ${ }^{\S}$ Instituto de Ciencias Naturales Alexander Von Humboldt, Universidad de Antofagasta, Antofagasta, Chile \\ "Finnish Museum of Natural History, University of Helsinki, Helsinki, Finland
}

\section{SUMMARY}

1. Climate change in recent decades has resulted in an increase in both the density and diversity of consumers in subarctic freshwater ecosystems. Despite this, harsh winter conditions in the region limit productivity and may serve as a bottleneck driving trophic interactions within the fish community, potentially determining the outcome of climate change for resident biota. However, due to the difficulties in sampling during winter months, few studies have assessed seasonal variation in the ecological interactions between native and range-expanding species in subarctic regions.

2. We examined seasonal variation in activity, diet (stomach content) and resource use $\left(\delta^{13} \mathrm{C}\right.$ and $\delta^{15} \mathrm{~N}$ stable isotope ratios) of two fishes: the resident cold-water-adapted European whitefish (Coregonus lavaretus L.) and the range-expanding cool-water-adapted ruffe (Gymnocephalus cernua L.) in lakes with low and high consumer density. Results were contrasted with seasonal availability of benthic and pelagic resources and indirect measures of individual fitness, that is condition, growth and estimated lipid content (muscle elemental $\mathrm{C}: \mathrm{N}$ ratio) of both species.

3. The effects of fish density were apparent in both the diet and resource use of whitefish, which altered their diet and displayed reduced stomach fullness during winter in high-density lakes. This was associated with an overall reduction in whitefish growth, condition and estimated lipid content in high-density lakes, which was especially pronounced during winter.

4. Ruffe utilised a greater proportion of profundal resources than whitefish in both summer and winter, potentially exploiting a vacant niche. Ruffe maintained condition and lipid reserves throughout the winter, highlighting the potential for further northward range expansion of the species.

5. Winter acts as a seasonal bottleneck in subarctic lakes, but assumptions that this bottleneck primarily selects against warmer-water-adapted invasive species such as ruffe may be too restrictive. The effects of seasonal resource depletion on fish condition and invertebrate density were most severe in lakes with a high density of fish, and in these conditions, the cold-water-adapted resident whitefish was most adversely affected.

Keywords: diet, resource competition, ruffe, stable isotopes, whitefish, winter ecology

\section{Introduction}

Climate change in recent decades has affected all levels of biological organisation (Brown et al., 2004; Tylianakis et al., 2008) and is disproportionally pronounced in Arctic and subarctic regions (IPCC, 2013). In subarctic freshwater ecosystems, recent warming has driven increased pelagic productivity (Sorvari, Korhola \& Thompson, 2002), while many species have exhibited poleward distribution shifts, an apparent response to increasing ambient temperature (Rahel \& Olden, 2008; Tylianakis et al., 2008; Comte et al., 2013). Although climate-related shifts in species distributions have been recorded in taxa ranging from plankton (Hays, Richardson \& Robinson,

Correspondence: Brian Hayden, Biology Department, University of New Brunswick, Fredericton, NB, E3B 5A3, Canada. E-mail: brian.hayden@ unb.ca 
2005) and freshwater fishes (Comte et al., 2013) to megafauna (Parmesan, 2006), the dual impacts of increased productivity and the invasion of new species on resident biota are often difficult to ascertain (Lowry et al., 2013). The majority of attempts to predict the outcomes of climate change for resident biota involve bioclimate envelope models which may underestimate the importance of biotic interactions in determining these outcomes (Araújo \& Peterson, 2012). Furthermore, in many cases the ecological processes underpinning the assumptions of these models are still poorly understood. Here, we draw on a detailed data set highlighting the interacting effects of increased consumer density and seasonal shifts in productivity on intra- and interspecific competition in subarctic fish communities.

In Arctic regions, trophic interactions must be viewed against a backdrop of severe annual variation (Hayden, Harrod \& Kahilainen, 2014a): Arctic summer consists of 1-2 months of 24-h sunlight and moderate air temperatures $\left(5-20^{\circ} \mathrm{C}\right)$, while the polar winter is characterised by 1-2 months of darkness, air temperatures between -30 and $-20{ }^{\circ} \mathrm{C}$ and snow cover of $0.5-1.5 \mathrm{~m}$. In lakes, these conditions drive a cycle of a brief productive period in late summer, followed by an extended period of low productivity coinciding with the ice-covered winter months (Rautio et al., 2011). Therefore, winter represents a seasonal bottleneck when resources become limited and when the relative competitive abilities of cold- and warm-adapted species are likely to be most distinct (Shuter et al., 2012). In this scenario, warm-adapted species have a competitive advantage relative to the coldadapted residents during the summer months, but the situation may be reversed in winter. Determining the outcome of intra- and interspecific trophic interactions during both seasons is therefore of fundamental importance to understanding the ecological processes in the wild and to improving the performance of predictive models. However, research examining resource competition is often conducted in a stable setting, either under controlled laboratory conditions or temporally limited field sampling, typically during the summer (Carmel et al., 2013). Thus, summer and winter sampling is required to determine how the theories derived from these stable state scenarios play out in natural environments.

The northernmost regions of Europe are characterised by a pronounced climatic gradient that mimics the range of future climatic predictions and also represent the current distribution limits of various species. Cold-wateradapted generalist fishes such as Arctic charr, Salvelinus alpinus, brown trout, Salmo trutta, and whitefish, Coreg- onus lavaretus, dominate the fish fauna of subarctic lakes. Summer air temperatures in the region have increased by $1-2{ }^{\circ} \mathrm{C}$ in the past four decades (Hayden, Harrod \& Kahilainen, 2014b), and cool-water-adapted percid species, most notably generalist perch, Perca fluviatilis, and the benthivorous specialist ruffe, Gymnocephalus cernua, have been recorded at latitudes above their historically documented distribution range, suggesting that the northern boundary of their distribution is changing (Hayden, Harrod \& Kahilainen, 2013a; Hayden et al., 2014b). These systems provide an excellent opportunity to conduct space-for-time analyses, examining seasonal influences on the outcome of competitive interactions between resident and range-expanding species (Fukami \& Wardle, 2005).

Recent investigations have revealed that diet and growth of whitefish, the most abundant species in these northern lakes, are strongly regulated by annual variation in their prey resources (Hayden et al., 2014a). In summer, whitefish are trophic generalists, feeding on a variety of benthic and pelagic prey (Kahilainen et al., 2007; Harrod, Mallela \& Kahilainen, 2010): in winter, however, they specialise on chironomid larvae as pelagic resources are scarce (Hayden et al., 2013a, 2014a). Further studies have shown that range-expanding ruffe in this region may restrict whitefish from benthic resources, such as chironomid larvae (Hayden et al., 2013b). Thus, this region serves as an ideal location to test the effect of seasonal variation in resource availability on both interand intraspecific interactions within the resident and invasive fish community.

We undertook summer and winter sampling in six subarctic lakes in Finnish Lapland, three lakes with low densities of consumers, predominantly whitefish (LD lakes), and three lakes containing both high densities of whitefish and invasive populations of ruffe (HD lakes). Our study was based on two principal hypotheses:

Hypothesis 1: We predicted that increased fish density would lead to a winter depletion of prey resources in HD lakes. We further hypothesised that this would result in intraspecific competition amongst whitefish evidenced by reduced growth, condition and lipid reserves in whitefish populations in HD lakes (Amundsen et al., 2002).

Hypothesis 2: In a previous study, we demonstrated that, in this region, ruffe derive a greater proportion of their energy from benthic resources than do native whitefish (Hayden et al., 2013b). Based on these findings, we predicted that diet and stable 
isotope ratios of ruffe would show increased utilisation of benthic resources in both seasons allowing them to maintain condition and lipid reserves through the year despite being situated above the northern limit of the species historical range (Ogle, 1998; Hayden et al., 2013b).

\section{Methods}

\section{Field sampling}

Field sampling was conducted at six oligotrophic lakes in subarctic Fennoscandia (Fig. 1; Table 1). Lakes were classified as either low density (LD), the northernmost lakes known to be whitefish-dominated (L. Kilpis, L. Siilas \& L. Kuohkima), or high density (HD), situated directly south and known to be whitefish-dominated but also containing ruffe (L. Ropi, L. Kivi and L. Oiko). L. Kivi also contains perch, which are practically absent from all other lakes (Hayden et al., 2013b). In L. Ropi, the whitefish population includes a generalist large sparsely rakered (LSR) whitefish morph and a planktivorous densely rakered (DR) morph (Harrod et al., 2010; Hayden et al., 2013b). In this study, we focus only on trophic interactions between ruffe and LSR whitefish (hereafter whitefish).

Summer (July-September) and winter (FebruaryMarch) sampling took place on single occasions between 2011 and 2013, except summer sampling in L. Siilas, which took place in 2007. Abiotic characteristics of the water column were measured at one-metre intervals from the surface to a maximum depth of $20 \mathrm{~m}$; light attenuation $( \pm 1 \mathrm{~m})$ was measured using a LI-COR LI-250A Light Meter (LI-COR Biosciences, Lincoln, NE, U.S.A.), and water temperature $\left( \pm 0.1^{\circ} \mathrm{C}\right)$ was measured using an YSI Professional Plus meter (YSI Inc., Yellow Springs, OH, U.S.A.). In winter, ice and snow depth $( \pm 1 \mathrm{~cm})$ were also measured, instruments were lowered through a hole cut in the ice and the hole was refilled with crushed ice before measurements were taken.

Benthic macroinvertebrate (BMI) communities were sampled using an Ekman grab (sampling area $272 \mathrm{~cm}^{2}$ ). Three replicate samples were taken from the littoral $(1 \mathrm{~m})$ and profundal $(20 \mathrm{~m}$ in L. Kilpis and the deepest point in all other lakes) habitats in each lake. Macroinvertebrates were identified to family level, counted and frozen for stable isotope analysis. Pelagic zooplankton (ZPL) were sampled using a zooplankton net $(50 \mu \mathrm{m}$ mesh; $25 \mathrm{~cm}$ diameter; three replicate tows) hauled vertically through the water column at the deepest point of each lake (20 m in L. Kilpis). ZPL were fixed in 5\% formalin solution. Additional composite ZPL samples (three replicates when abundance permitted) were collected at each sampling occasion for stable isotope analysis.

Fish were sampled using benthic set gill nets. Each net series consisted of seven panels of monofilament mesh $(1.8 \times 30 \mathrm{~m}$; knot-to-knot mesh sizes: 12, 15, 20, 25, 30, 35 and $45 \mathrm{~mm}$ ) and a Nordic multimesh net comprised of twelve $1.5 \times 25 \mathrm{~m}$ panels (mesh sizes 5$55 \mathrm{~mm}$ ). In summer, the net series were set overnight for $12 \mathrm{~h}$ along a depth profile ranging from $2 \mathrm{~m}$ to the

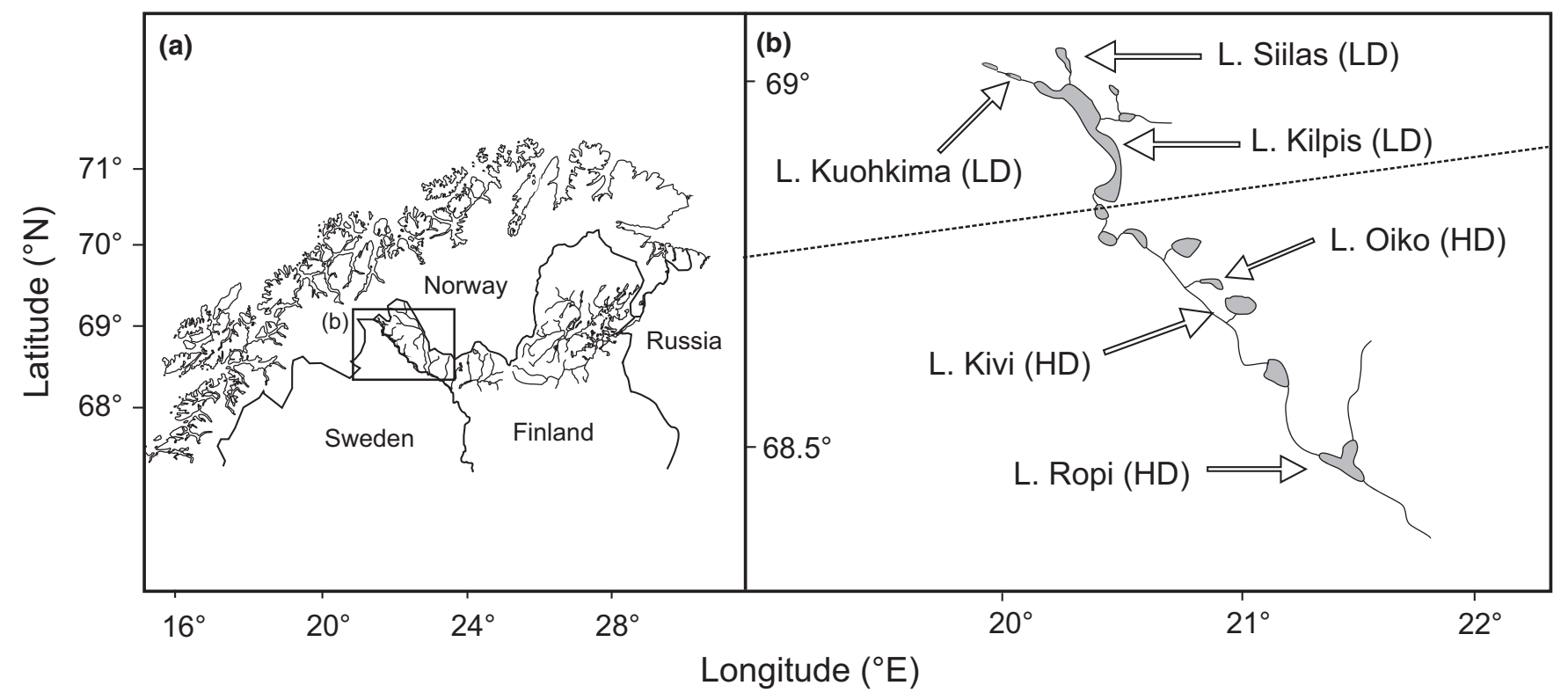

Fig. 1 Northern Fennoscandia showing (a) the study region and (b) the location of low-density whitefish-dominated (LD) and high-density whitefish and ruffe (HD) lakes. The broken line indicates the current distribution limit of ruffe in the study watercourse. 
Table 1 Physical and environmental characteristics of low-density (LD) and high-density (HD) sites

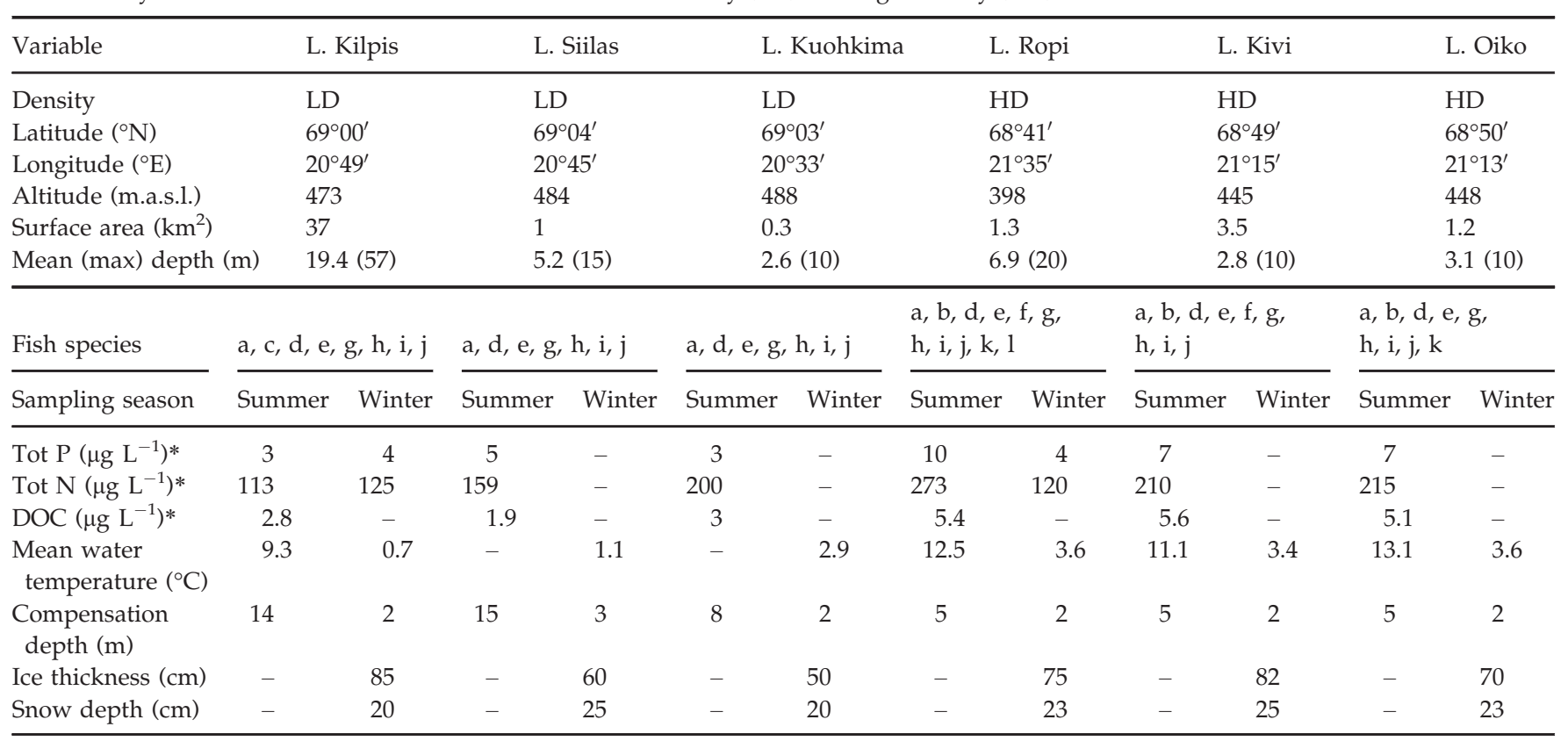

Fish species: (a) whitefish; (b) ruffe; (c) Arctic charr Salvelinus alpinus; (d) grayling Thymallus thymallus; (e) minnow Phoxinus phoxinus; (f) perch Perca fluviatilis; (g) pike Esox lucius; (h) burbot Lota lota; (i) brown trout Salmo trutta; (j) alpine bullhead Cottus poecilopus; (k) roach Rutilus rutilus; (1) ide Leuciscus idus. Compensation depth defines the border of productive layer, that is depth where $1 \%$ of surface light is left.

*Water chemistry data obtained from Lapland Centre for Economic Development, Transport and Environment and courtesy of S. Taipale.

deepest point in each lake (16 $\mathrm{m}$ in L. Kilpis). In winter, nets were set under the ice following the protocol of Hayden et al. (2013a) and retrieved after 24-48 h. Fish were identified to species, and total length $( \pm 1.0 \mathrm{~mm})$ and blotted wet mass $( \pm 0.1 \mathrm{~g})$ were recorded. Fish were subdivided into invertebrate-consuming fish, that is species that prey on invertebrates (predominantly whitefish and ruffe), and piscivores (pike Esox lucius). Many fishes in these lakes (i.e. burbot, brown trout and Arctic charr) undergo an ontogenetic shift from invertebrate to fish feeding; thus, individuals under $25 \mathrm{~cm}$ total length were classified as invertebrate-consuming fish, whereas individuals over $25 \mathrm{~cm}$ total length were classed as piscivores (Kahilainen \& Lehtonen, 2003). Perch undergo a similar ontogenetic shift, but previous studies in the region indicate that this occurs at $20 \mathrm{~cm}$ total length (Hayden et al., 2014b); thus, perch below this size were classified as invertebrate-consuming fish. Catch-per-uniteffort (CPUE: $n$ net series ${ }^{-1} \mathrm{~h}^{-1}$ ) and biomass-per-uniteffort (BPUE: $g$ net series ${ }^{-1} h^{-1}$ ) were calculated for each species on each occasion to provide a proxy for fish activity level and total biomass, respectively (Hayden et al., 2013a). CPUE and BPUE analyses were restricted to invertebrate-consuming fish as these are of direct relevance to the whitefish-ruffe trophic interaction. Fulton's condition factor $(k)$ was calculated for each fish, and both sagittal otoliths were removed from each fish for age analysis (Bagenal \& Tesch, 1978).

\section{Laboratory analysis}

Benthic macroinvertebrate and ZPL families were combined to functional groups for abundance and dietary analyses. Littoral and profundal density of each BMI group $\left(n \mathrm{~m}^{-2}\right)$ and total ZPL density $\left(n \mathrm{~L}^{-1}\right)$ were estimated from summer and winter samples. Nauplii or copepodite stages of zooplankton were not counted as they are not consumed by adult whitefish in this region (Kahilainen, Alajärvi \& Lehtonen, 2005).

A representative subsample $(n=100)$ of whitefish and ruffe was analysed, and stomach contents, principally zooplankton and BMIs, were identified to family level. The relative contribution of each family to total stomach fullness was estimated on a scale of $0-10$, where 0 represents empty and 10 represents a fully extended stomach (Swynnerton and Worthington 1940).

Dorsal muscle tissue was dissected from a subsample of each species ( $n=50$, when possible). Fish muscle, BMI and ZPL samples were freeze-dried $\left(48 \mathrm{~h}\right.$ at $\left.-70{ }^{\circ} \mathrm{C}\right)$ and ground to a fine powder, and a $0.5 \pm 0.1 \mathrm{mg}$ subsample was encapsulated in a tin cup. Elemental carbon (C) and nitrogen $(\mathrm{N})$ levels were determined using a FlashEA 
1112 elemental analyser (summer samples) or a Carlo Elba NC2500 (winter samples). Carbon $\left(\delta^{13} \mathrm{C}\right)$ and nitrogen $\left(\delta^{15} \mathrm{~N}\right)$ stable isotope values were subsequently determined using a Thermo Finnigan Delta ${ }^{\text {PLUS }}$ Advantage mass spectrometer Thermo Finnegan, Bremen, Germany. Isotope values are presented relative to international standards [carbon: NBS19 carbonate (PDBV); nitrogen: atmospheric nitrogen]. Repeated analysis of an in-house standard (pike muscle tissue) revealed that analytical error (SD) for $\delta^{13} \mathrm{C}$ and $\delta^{15} \mathrm{~N}$ was $0.1 \%$.

\section{Data analysis}

Invertebrate community structure. Seasonal variation in the density of littoral and profundal BMI and pelagic ZPL communities was assessed using PERMANOVA, a nonparametric analogue of ANOVA based on a similarity matrix (McArdle and Anderson 2001). A Bray-Curtis similarity matrix was created from the non-transformed density values of each community. A four-factor PERMANOVA (density: fixed, high/low; lake: fixed, six levels; season: fixed, summer/winter; depth: fixed, littoral/ profundal) was performed on the BMI data set. The factor depth was removed when analysing the ZPL data set. PERMANOVAs were performed using PRIMER 6 ver. 1.0.2 (Primer-E, Plymouth, U.K.).

Stomach content. A four-factor PERMANOVA (density: fixed, high/low; lake: fixed, six levels; season: fixed, summer/winter; species: fixed, whitefish/ruffe) performed on a Bray-Curtis similarity matrix of stomach content data was conducted to address the hypotheses laid out above. Pairwise PERMANOVA comparisons of each species in each lake were performed to test for seasonal variation in the diet of ruffe and whitefish independently. In addition, pairwise comparisons within each sample were used to identify dietary overlap between the species on each occasion. Where significant variation was observed, analysis of similarities (SIMPER) was used to determine which prey types were responsible for the variation. Standardised Levins index of dietary niche width was calculated for each individual (Levins, 1968). As Levins' niche width is affected by sample size, data were subsampled using random numbers to achieve equal sample sizes prior to further analysis. Seasonal and interspecific variation in mean stomach fullness and niche width was then examined using nonparametric Welch $t$-tests.

Stable isotope analysis. As lipids are depleted in ${ }^{13} \mathrm{C}$ relative to muscle tissue, $\delta^{13} \mathrm{C}$ values were arithmetically transformed prior to analysis (Kiljunen et al., 2006). A Euclidean distance matrix was created from $\delta^{13} \mathrm{C}$ and $\delta^{15} \mathrm{~N}$ values, and a pairwise PERMANOVA (design as per stomach content) was used to determine seasonal and interspecific variation in the $\delta^{15} \mathrm{~N}-\delta^{13} \mathrm{C}$ centroid of both species in each lake. The Stable Isotope Analysis in $\mathrm{R}$ (SIAR) mixing model (Parnell et al., 2010) was employed to identify the predominant resource use of each species. Mean $( \pm \mathrm{SD})$ annual littoral and profundal BMI, and ZPL values were calculated for each lake and used as baseline values for the analysis (values provided in Table S1). Due to overlap between the profundal BMI and ZPL values in some lakes, we constrained the model using stomach content data. The mean proportion of benthic (BMI) and pelagic (ZPL and surface insects) prey in the stomach content of each sample was calculated, and the benthic prey subsequently subdivided into littoral and profundal values at a ratio of $1: 1$. These mean littoral, profundal and pelagic values were inputted as prior data into the model using the SIARELICIT function. Standard mean \pm SD trophic fractionation values for muscle $\left(\Delta^{13} \mathrm{C}=1.3 \pm 0.3, \Delta \Delta^{15} \mathrm{~N}=2.9 \pm 0.3 \%\right.$ ) were used (McCutchan et al., 2003). Isotopic niche width of each species, calculated as a standard ellipse of the distribution of $\delta^{13} \mathrm{C}$ and $\delta^{15} \mathrm{~N}$ values, was calculated using the Stable Isotope Bayesian Ellipses in R (SIBER) analysis (Jackson et al., 2011). SIAR mixing models and Welch $t$-tests were conducted in $\mathrm{R}$ ver. 3.1.2 ( $\mathrm{R}$ Core Team, 2014).

Fish activity and condition. Welch $t$-tests were performed on BPUE and CPUE values for each species to examine the seasonal variation in fish activity of each species in each lake. Seasonal variation in mean condition factor $(k)$ and $\mathrm{C}: \mathrm{N}$ ratio (a proxy for lipid concentration) of both species were also examined using Welch $t$-tests. Fish age was estimated from burned and cracked otoliths collected in summer, and we calculated the mean length-atage values, a proxy for growth (Bagenal \& Tesch, 1978). The mean length-at-age values of whitefish in LD and HD lakes were compared using paired Welch $t$-tests.

\section{Results}

\section{Fish community}

The mean $( \pm \mathrm{SD})$ BPUE of invertebrate consumer fishes in HD (385 \pm 236$)$ and LD (378 \pm 213$)$ lakes was similar (Fig. 2a), but the relative abundance, CPUE, in HD $(11.1 \pm 4.8)$ lakes far exceeded that of $\operatorname{LD}(2.4 \pm 1.7)$ lakes (Fig. 2a; Table S2). Whitefish comprised 97-99\% of 
Fig. 2 Fish community structure in lowdensity (LD) and high-density (HD) systems: (a) variation in the biomass (BPUE, left axis) and density (CPUE, right axis) of whitefish (white), ruffe (black) and other fishes (grey); (b) the distribution of mass (left axis) and total length (right axis) values of whitefish, bold horizontal lines indicate median value, boxes represent upper and lower quartiles, and whiskers represent 1.5 times the quartile range; (c) age frequency distribution of whitefish; (d) mean length-at-age of whitefish and ruffe, growth curves are indicated by a cubic smoothing spline fitted to the length-at-age data for each species ( spar $=0.35$ ), and error bars denote 1 standard deviation. BPUE, biomass-per-unit-effort; CPUE, catch-perunit-effort.
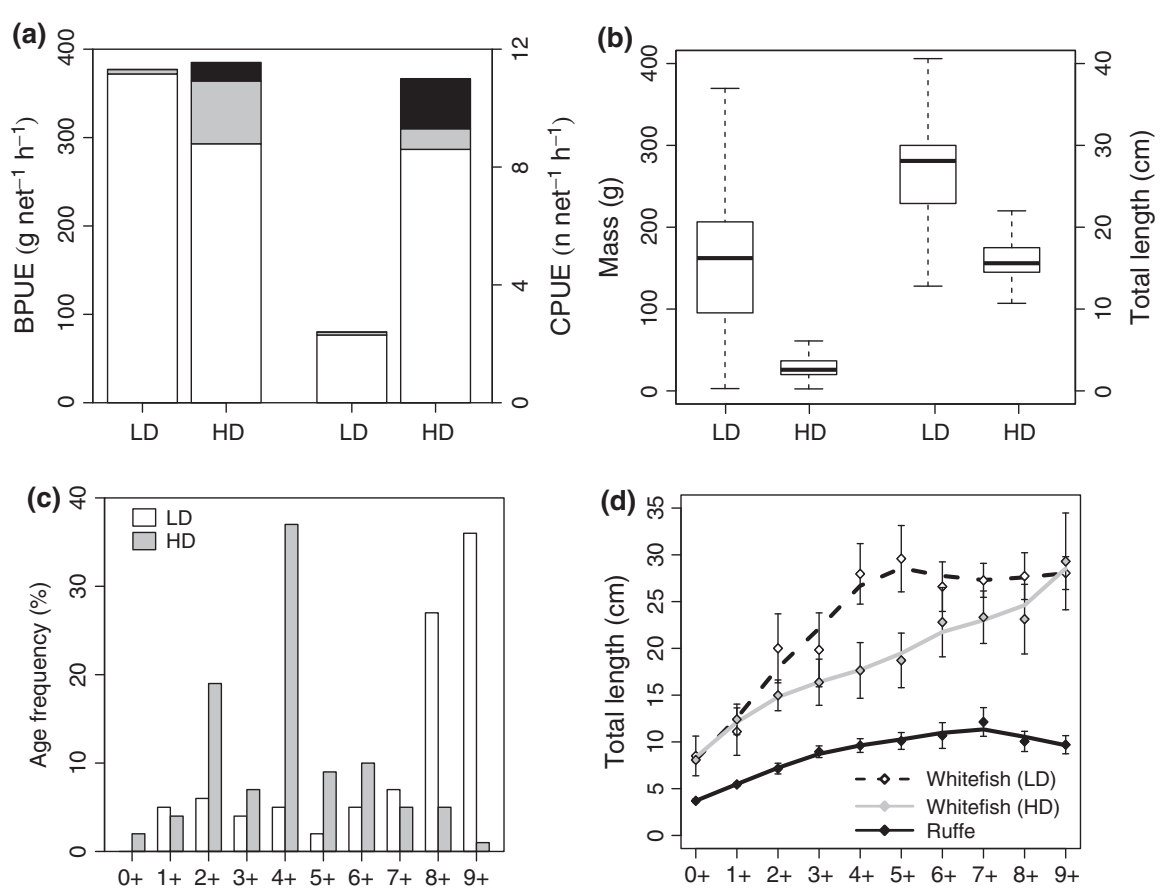

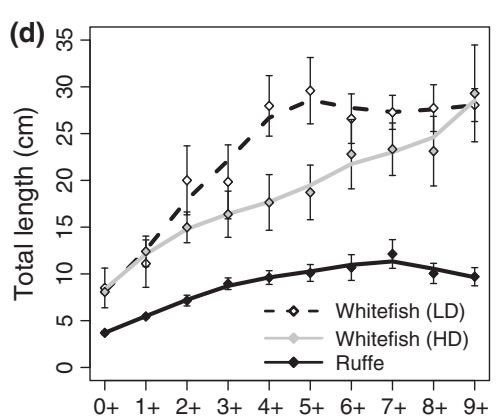

the BPUE of summer catch of invertebrate consumer fish in LD lakes and $90-92 \%$ of invertebrate consumer fish BPUE in L. Oiko and L. Ropi (Fig. 2a, Table S2). A large BPUE of $<20 \mathrm{~cm}$ TL perch was observed in L. Kivi; consequently, whitefish only accounted for $56 \%$ of invertebrate consumer fish biomass in this lake (Table S2). In HD lakes, summer catches of ruffe accounted for $2 \%$ of total invertebrate consumer fish BPUE in L. Ropi, $6 \%$ in L. Kivi and 7\% in L. Oiko. The mean BPUE of (all pike, $>20 \mathrm{~cm}$ perch and $>25 \mathrm{~cm}$ brown trout, Arctic charr and burbot), in HD lakes $\left(450 \pm 1880 \mathrm{~g}\right.$ net series $\left.{ }^{-1} \mathrm{~h}^{-1}\right)$ greatly exceeded that of LD lakes $(31 \pm 45)$. Seasonal variation in BPUE and CPUE was treated as a response to variation in water temperature and is outlined below.

The mean total length of whitefish in LD lakes $(25.7 \pm 6.1 \mathrm{~cm})$ exceeded that observed in HD lakes $(16.4 \pm 3.4 \mathrm{~cm}$; Fig. 2c). Mean total length of whitefish differed between seasons (Welch $t$-test: $t=2.88$, d.f. $=798.97, P<0.01)$ in LD lakes, but this was unlikely to confer any biological significance as summer $(26.2 \pm 6.6 \mathrm{~cm})$ and winter $(25.0 \pm 5.3 \mathrm{~cm})$ values were comparable. No variation in mean TL of whitefish was evident between summer $(16.5 \pm 3.8 \mathrm{~cm})$ and winter $(16.4 \pm 3 \mathrm{~cm})$ in HD lakes $(t$-test: $t=1.31$, d.f. $=2182.0$, $P=0.19$ ). The whitefish population in LD lakes was dominated by $8+$ and $9+$ individuals, whereas younger fish (4+) dominated the populations in HD lakes (Fig. 2c). Mean length-at-age values of whitefish in LD lakes exceeded those in HD lakes (paired $t$-test: d.f. $=10, t=2.76, P=0.02)$, although the difference was most evident in fish aged two and older (Fig. 2d; values presented in Table S3).

\section{Invertebrate community structure}

Benthic macroinvertebrate communities were dominated by chironomid larvae (mean $\% \pm$ SD: $51 \pm 25$ ) and oligochaetes $(23 \pm 24)$, although variation was evident between lakes (Table S4). Littoral BMI density exceeded profundal in all lakes and seasons (Pseudo $F_{1.46}=19.36$, $P<0.01$; Fig. 3). The mean density of littoral BMIs in LD lakes exceeded that of HD lakes (Pseudo $F_{1.32}=4.68$, $P<0.01)$. Seasonal variation was not evident across the data set (Pseudo $F_{1.32}=1.46, P=0.17$ ), but a significant density*season interaction was observed (Pseudo $\left.F_{1.32}=3.27, P<0.01\right)$ due to a seasonal decline in BMIs in HD lakes (PERMANOVA: $t=1.76$, d.f. $=16, P=0.03$; Fig. 3). In contrast, the profundal BMIs was not affected by the density of invertebrate-consuming fish (Pseudo $F_{1,30}=1.57, P=0.17$ ) or season (Pseudo $F_{1.30}=1.29$, $P=0.25)$.

The zooplankton fauna of LD lakes was dominated by calanoid copepods (mean \% of abundance: 59-89\%), whereas a greater proportion of cladocerans, Bosmina sp. and Daphnia sp., were observed in HD lakes (values provided in Table S5). The density of zooplankton in LD lakes exceeds that of $\mathrm{HD}$ lakes (Pseudo $F_{1.32}=5.81$, $P<0.01$; Fig. 3), and summer densities exceed winter across the study sites (Pseudo $F_{1.32}=10.48, P<0.01$; Fig. 3). 


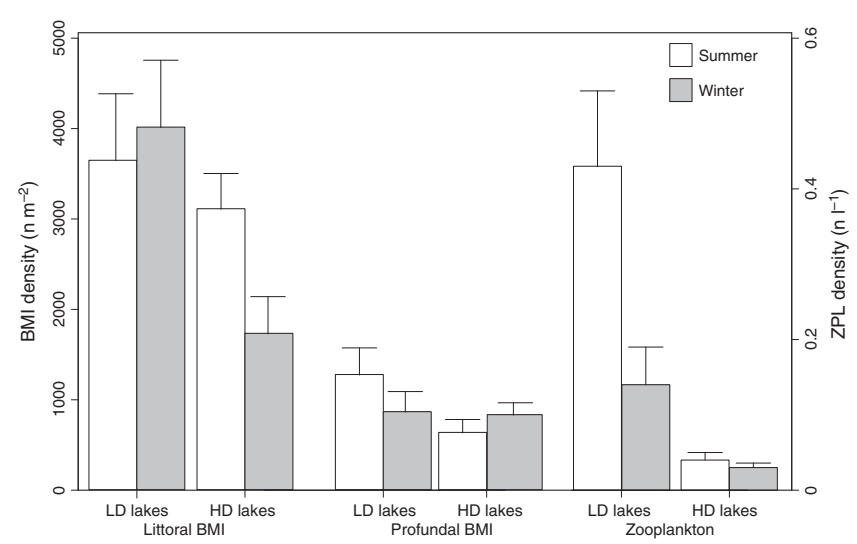

Fig. 3 Mean density of density of littoral and profundal benthic macroinvertebrates (BMI), and zooplankton (ZPL) observed in summer (white bars) and winter (grey bars) in low-density (LD) and high-density (HD) systems. Error bars denote standard error.

H1 - Effect of consumer density on seasonal variation in trophic ecology and condition of whitefish

Whitefish stomach content varied between lake density types (Pseudo $F_{1.967}=66.28, \quad P<0.01$ ) and season (Pseudo $F_{1.967}=131.55, P<0.01$ ). In LD lakes, whitefish shifted from a generalist diet of benthic invertebrates and zooplankton in the summer, to a diet dominated by chironomid larvae (mean 70-83\%) in the winter (Fig. 4; Table S6). Associated with this was a reduction in dietary niche width in L. Kilpis and L. Kuohkima, but not in L.
Siilas where the summer diet was dominated by chironomid pupae (Fig. 4, Tables 2 \& S6). In HD lakes, the summer diet of whitefish was also a typical of a generalist; however, in winter, chironomid larvae were the dominant prey only in L. Kivi $(66 \% \pm 43)$, whereas whitefish diet was dominated by molluscs in L. Ropi $(71 \% \pm 41)$ and pelagic copepods in L. Oiko $(51 \% \pm 47)$. In HD lakes, a seasonal shift in dietary niche width of whitefish was evident only in L. Ropi (Tables 2 \& S6). Whitefish stomach fullness in LD lakes exceeded HD lakes in both summer (mean \pm SD; LD: $4.02 \pm 1.91 ;$ HD: $3.22 \pm 2.44$; $t$-test: $t=4.89$, d.f. $=698.42, \quad P<0.01)$ and winter (LD: $3.03 \pm 2.52 ; \mathrm{HD}: 1.62 \pm 1.91$; $t$-test: d.f. $=t=7.36,536.67$, $P<0.01)$.

In LD lakes, seasonal variation in the location of the whitefish $\delta^{15} \mathrm{~N}-\delta^{13} \mathrm{C}$ centroid was evident in L. Kilpis and L. Kuohkima (Tables $2 \&$ S7), but differences were small, and likely not biologically meaningful (Fig. 5a,b). Seasonal variation in the isotopic niche width of whitefish, observed in all lakes except L. Kilpis, typically related to a reduced niche width in winter (Fig. 5c; Tables 2 \& S7). In HD lakes, seasonal variation in the location of the whitefish $\delta^{15} \mathrm{~N}-\delta^{13} \mathrm{C}$ centroid was evident in L. Kivi (Tables 2 \& S7), but again differences were small (Fig. 5a,b). Isotopic niche width of whitefish was reduced in winter in L. Kivi and L. Oiko but increased in L. Ropi (Fig. 5c, Tables 2 \& S7).
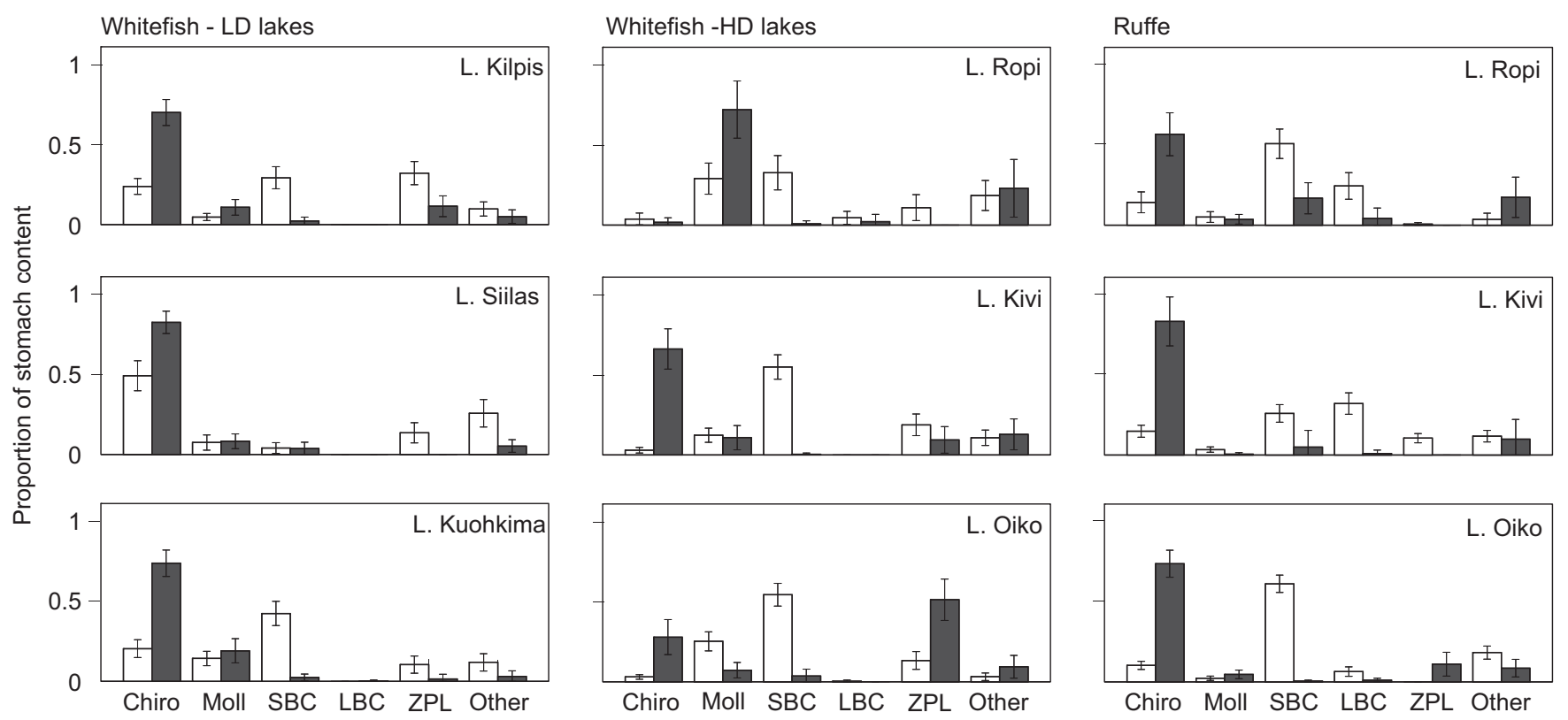

Fig. 4 Mean relative abundance of prey in the summer (white bars) and winter (grey bars) stomach content of ruffe and whitefish. Chiro refers to Chironomid larvae and pupae; Moll (Mollusc) includes Valvata sp., Lymnaea sp. and Pisidium sp.; SBC refers to small benthic crustaceans (Eurycercus spp., Megacyclops spp., Ostracoda); LBC refers to large benthic crustaceans (Gammarus lacustris, Asellus aquaticus); ZPL refers to pelagic zooplankton (Bosmina sp., Daphnia sp., Calanoida, Cyclopoida); Other includes Hydracarina, decomposed material, fish eggs and surface insects). Error bars denote 95\% CL. 
Table 2 Seasonal variation in trophic ecology of whitefish and ruffe

\begin{tabular}{|c|c|c|c|c|c|c|c|c|c|c|c|c|c|c|c|}
\hline \multirow[b]{2}{*}{ Density } & \multirow[b]{2}{*}{ Species } & \multirow[b]{2}{*}{ Lake } & \multicolumn{3}{|c|}{ SCA } & \multicolumn{3}{|c|}{ Fullness } & \multicolumn{3}{|l|}{ Levins } & \multicolumn{3}{|l|}{ SIA } & \multirow{2}{*}{$\frac{\text { SEAc }}{P}$} \\
\hline & & & d.f. & $t$ & $P$ & d.f. & $t$ & $P$ & d.f. & $t$ & $P$ & d.f. & $t$ & $P$ & \\
\hline \multirow{2}{*}{ LD } & \multirow{2}{*}{ Whitefish } & L. Siilas & 160 & 4.27 & $<0.01$ & 148.66 & 1.29 & 0.19 & 125.26 & -1.39 & 0.17 & 87 & 1.29 & 0.22 & 0.99 \\
\hline & & L. Kuohkima & 176 & 6.79 & $<0.01$ & 139.6 & -0.76 & 0.45 & 126.78 & 2.58 & $<0.01$ & 69 & 3.11 & $<0.01$ & 0.99 \\
\hline \multirow[t]{4}{*}{ HD } & Whitefish & L. Ropi & 76 & 3.02 & $<0.01$ & 70.68 & 0.89 & 0.38 & 35.40 & 2.43 & 0.02 & 82 & 1.41 & 0.16 & 0.04 \\
\hline & \multirow[t]{3}{*}{ Ruffe } & L. Ropi & 99 & 4.66 & $<0.01$ & 117.99 & 7.18 & $<0.01$ & 43.89 & 0.53 & 0.60 & 82 & 0.91 & 0.39 & 0.29 \\
\hline & & L. Kivi & 150 & 4.87 & $<0.01$ & 35.08 & 1.67 & 0.11 & 23.46 & 4.38 & $<0.01$ & 65 & 3.14 & $<0.01$ & 0.92 \\
\hline & & L. Oiko & 204 & 12.57 & $<0.01$ & 228.55 & 1.57 & 0.12 & 82.93 & 5.39 & $<0.01$ & 80 & 1.54 & 0.1 & 0.31 \\
\hline
\end{tabular}

Stomach content (SCA) and $\delta^{15} \mathrm{~N}-\delta^{13} \mathrm{C}$ centroid (SIA) values detail pairwise PERMANOVA performed on the respective data sets. Stomach fullness and niche width (Levins) values detail the results of Welch $t$-tests. Isotopic niche width (SEAc) is the likelihood that summer niche width exceeded winter. Statistically significant values $(\alpha=0.05)$ are presented in bold. Stomach content, stomach fullness and Levins' niche width values are reported in Table S6, and $\delta^{13} \mathrm{C}, \delta^{15} \mathrm{~N}$, SEAc values and the results of the Stable Isotope Analysis in R mixing model are reported in Table S5.

Stable isotope mixing models revealed greater variation in resource use between lakes than community density or season (Fig. 6, mode and 95\% credibility limits of each sample are presented in Table S7). In both seasons, profundal BMIs were the predominant prey of whitefish in L. Kilpis (Fig. 6c), whereas littoral BMIs were dominant in L. Siilas (Fig. 6b). Seasonal variation was uniquely evident in L. Kuohkima as whitefish shifted from pelagic zooplankton in summer to littoral BMIs in winter (Fig. 6a,b). In HD lakes, whitefish predominantly assimilated energy from littoral BMIs in L Ropi and L. Kivi, while zooplankton were of greater importance in L. Oiko (Fig. 6, Table S7). Seasonal variation in resource use was marginal in all HD lakes, although the consumption of profundal BMIs increased in winter in L. Ropi (Table 2; Fig. 6c).

Catch-per-unit-effort of whitefish was lower in winter than in summer in all lakes (Table 3; Fig. 7a). Mean $( \pm \mathrm{SD})$ condition factor of whitefish was higher in LD lakes than in HD lakes in both summer (LD: $0.85 \pm 0.60$; HD: $0.73 \pm 0.15$; $t$-test: d.f. $=308.87, t=3.27, P<0.01$ ) and winter (LD: $0.68 \pm 0.06 ; \mathrm{HD}: 0.64 \pm 0.09 ; t$-test: d.f. $=357.87, \quad t=5.91, \quad P<0.01$; values presented in Table S2). The mean condition factor of whitefish was lower in winter than in summer in most cases, although the difference was not significant in L. Kilpis or L. Ropi (Fig. 7b, Tables 2 \& S2). Similarly, the $\mathrm{C}: \mathrm{N}$ ratio of whitefish, a proxy for lipid reserves, was higher in LD lakes than in HD lakes in both summer (LD: $3.3 \pm 0.2$; HD: $3.2 \pm 0.1$; $t$-test: d.f. $=130.44, t=5.49, P<0.01)$ and winter (LD: $3.2 \pm 0.1$; HD: $3.1 \pm 0.1$; $t$-test: d.f. $=218.09$, $t=11.12, P<0.01$; Fig. 7c; values presented in Table S2). Seasonal differences in $\mathrm{C}: \mathrm{N}$ ratio were minimal $\mathrm{LD}$ lakes other than L. Siilas, where samples were separated by a period of 4 years. In contrast, $\mathrm{C}: \mathrm{N}$ ratios decreased from summer to winter in all HD lakes (Fig. 7c, Tables 3 \& S2).

H2 - Seasonal variation in the resource use and condition of ruffe

Ruffe predominantly fed on benthic prey, although the exact prey group varied between seasons (Pseudo $F_{1,453}=112.73, P<0.01$; Table 2$)$. In summer, ruffe diet was typical of a specialist benthivore (Fig. 4). Eurycercus sp. and Megacyclops were the dominant prey group in L. Ropi (mean \pm SD: $50 \pm 37$ ) and L. Oiko $(60 \pm 31)$, whereas Gammarus lacustris and Asellus aquaticus were dominant in L. Kivi $(32 \pm 39)$. In winter, ruffe diet was dominated (56-83\%) by chironomid larvae in all lakes (Fig. 4; Table S6). Ruffe dietary niche width was greater in summer than in winter in L. Kivi and L. Oiko, although no difference was evident in L. Ropi (Tables 2 \& S6). Stomach fullness was indistinguishable between summer and winter in L. Kivi and L. Oiko (Tables 2 \& S6).

Whitefish and ruffe consumed different prey when assessed across the data set (PERMANOVA lake*season*species interaction: Pseudo $F_{2,1412}=9.15, P<0.01$; Fig. 4; pairwise comparisons presented in Table S8). SIMPER analyses revealed that in summer, this was due to greater abundance of small (32\% of total variation) and large (14\%) benthic crustaceans in the diet of ruffe, and a greater proportion of molluscs (15\%) and pelagic zooplankton (13\%) in the diet of whitefish (Fig. 4, Table S6). In winter, variation in the abundance of chironomid larvae $(39 \%)$, zooplankton $(26 \%)$ and molluscs 

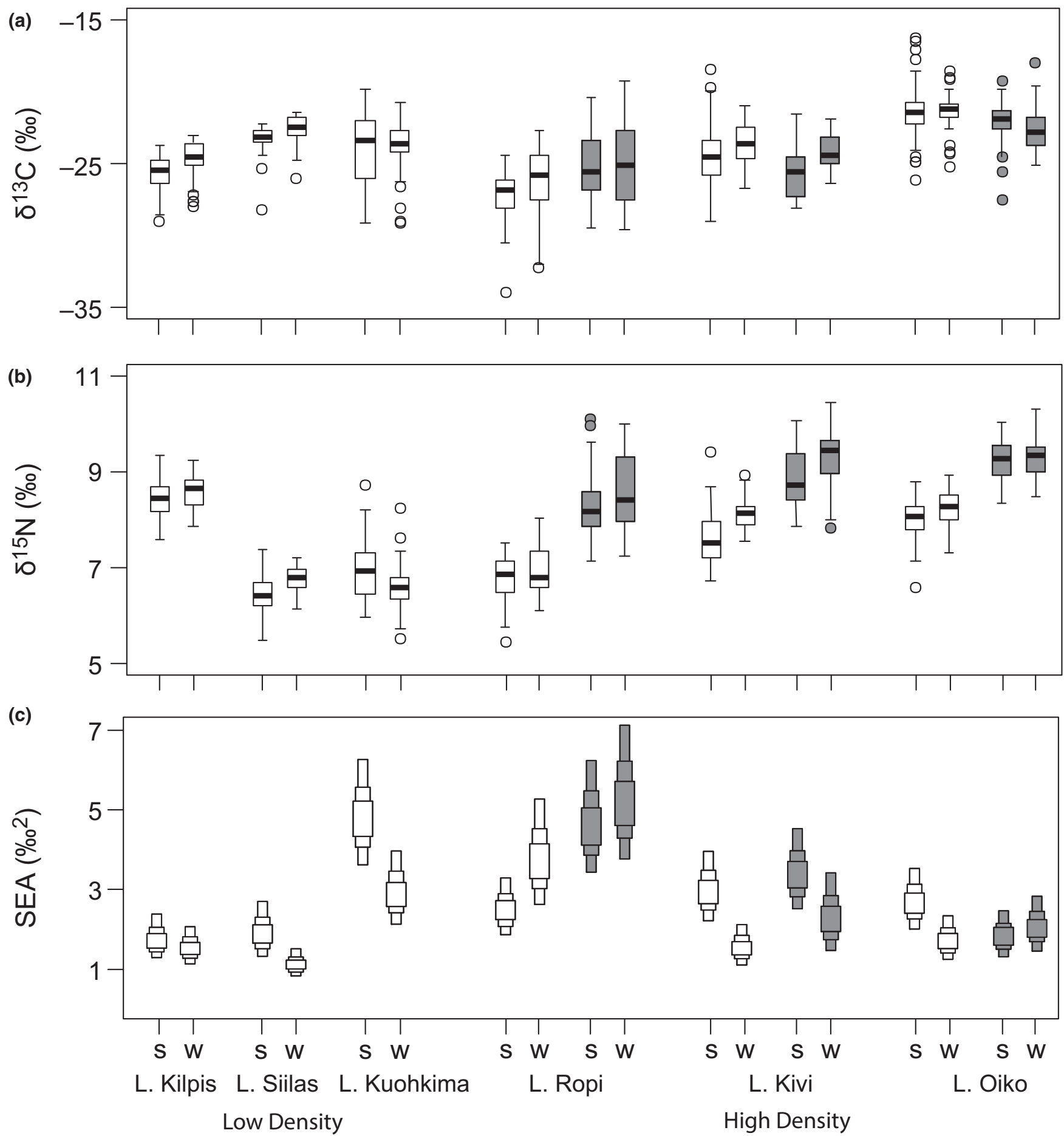

Fig. 5 Variation in (a) $\delta^{13} \mathrm{C}$, (b) $\delta^{15} \mathrm{~N}$ values and (c) the isotopic niche width of whitefish (white bars) and ruffe (grey bars). Summer (S) and winter (W) values are presented for each species. In (a) and (b), bold horizontal lines indicate the median, bars represent upper and lower quartiles, whiskers represent 1.5 times the quartile range or the maximum/minimum value, and outliers are presented as circles. Gradations in (c) indicate 25, 50 and 75\% credibility limits for each species. Lake Kilpis, Siilas and Kuohkima represent low-density lakes, whereas Lakes Ropi, Kivi and Oiko are high-density lakes.

(14\%) drove the differences between species (Fig. 4). In L. Kivi, both whitefish and ruffe predominantly fed on chironomid larvae (whitefish: $66 \pm 43$; ruffe: $83 \pm 32$ ).
Whitefish dietary niche typically exceeded that of ruffe in summer, but differences were less apparent in winter (Tables S6 \& S8). Stomach fullness of ruffe was greater 
Fig. 6 The relative contribution of (a) pelagic, (b) littoral and (c) profundal resources to the diet of whitefish (white bars) and ruffe (grey bars) as determined by the Stable Isotope Analysis in R (SIAR) mixing model. Summer (S) and winter $(W)$ values are displayed for each species. Gradations denote 50, 75 and 95\% credibility limits.
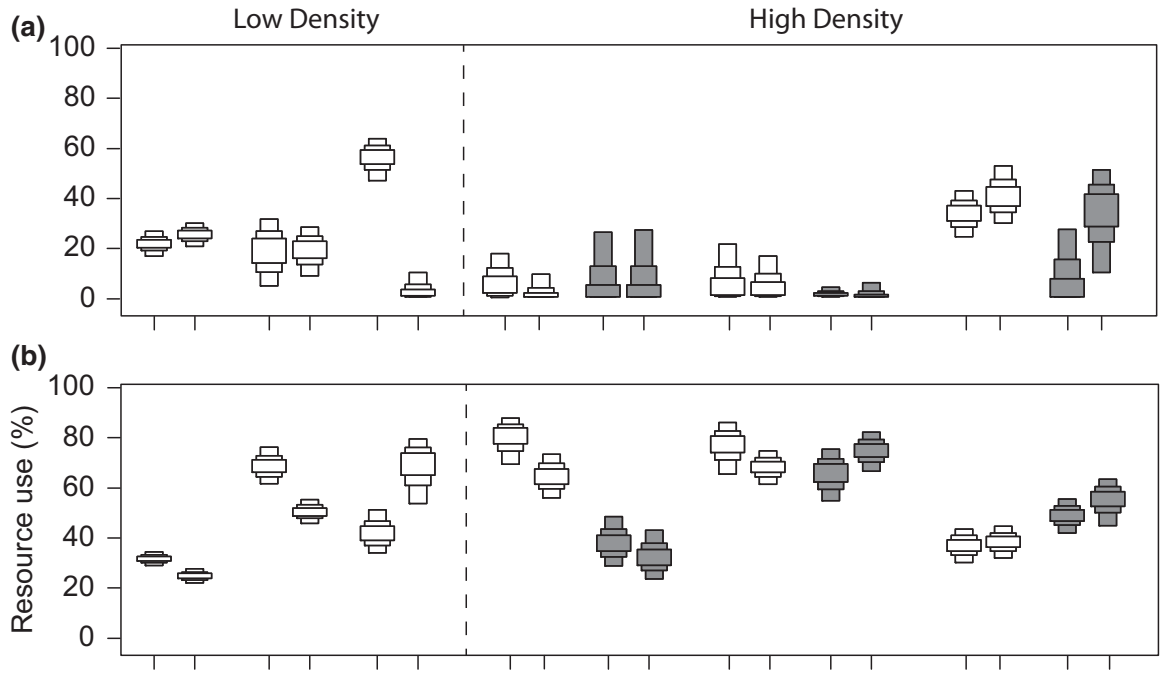

(c)

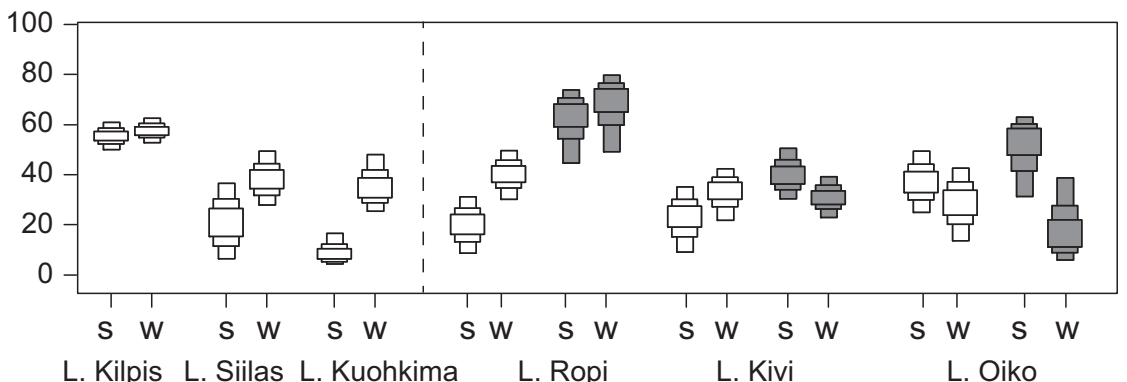

Table 3 Seasonal variation in the activity level proxy (Catch-per-unit-effort, CPUE), Fulton's condition factor ( $k$ ) and C : N (a proxy for lipid content) of whitefish and ruffe

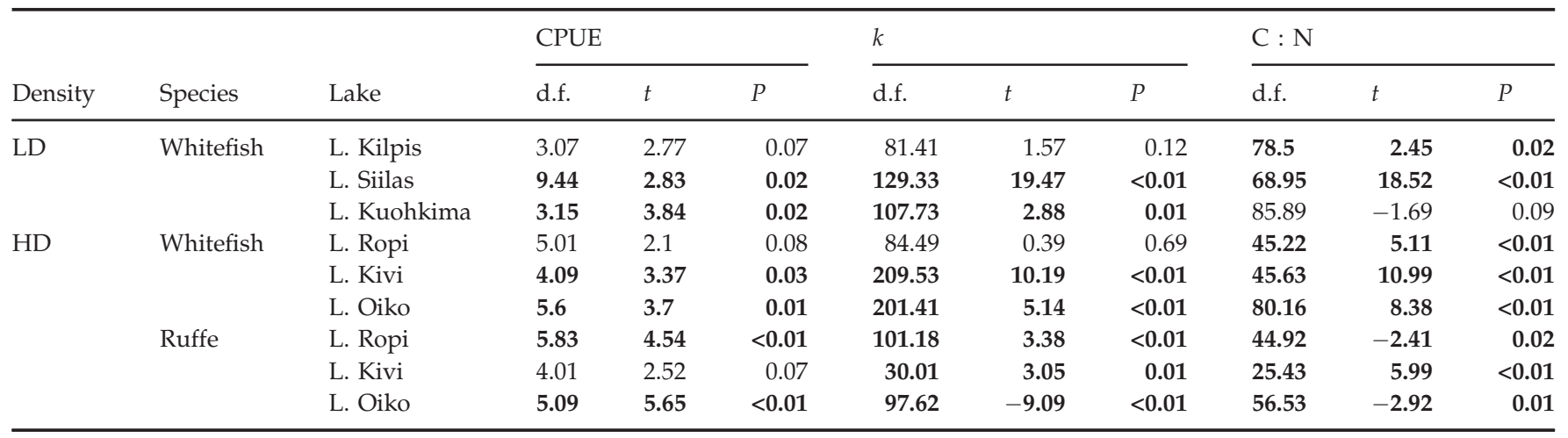

Values relate to a Welch $t$-test of mean summer and winter values. Statistically significant values $(\alpha=0.05)$ are presented in bold. Mean $( \pm \mathrm{SD}) \mathrm{CPUE}, k$ and $\mathrm{C}: \mathrm{N}$ values are reported in Table S2.

than that of whitefish in all but one case, winter in L. Ropi (Tables S6 \& S8).

Seasonal variation in the $\delta^{15} \mathrm{~N}-\delta^{13} \mathrm{C}$ centroid of ruffe was evident in L. Kivi (Table 2) and related to an enrichment of both ${ }^{13} \mathrm{C}$ and ${ }^{15} \mathrm{~N}$ in winter (Fig. 5, Table S7). The SIAR mixing model indicated that ruffe predominantly foraged on profundal (L. Ropi) or littoral (L. Kivi, L. Oiko) prey, with relatively small variation between (C) 2015 John Wiley \& Sons Ltd, Freshwater Biology, 60, 1000-1015 seasons, a notable exception was L. Oiko, where an increase in pelagic feeding was observed in winter (Fig. 6, Table S7). Isotopic niche width (SEA) of ruffe decreased between seasons in L. Kivi, but no variation was evident in the other lakes (Fig. 5, Tables 2 \& S7).

The $\delta^{15} \mathrm{~N}-\delta^{13} \mathrm{C}$ centroids of whitefish and ruffe differed in each sample (pairwise PERMANOVA presented in Table S8, Fig. 5a,b) showing a general lack of isotopic 

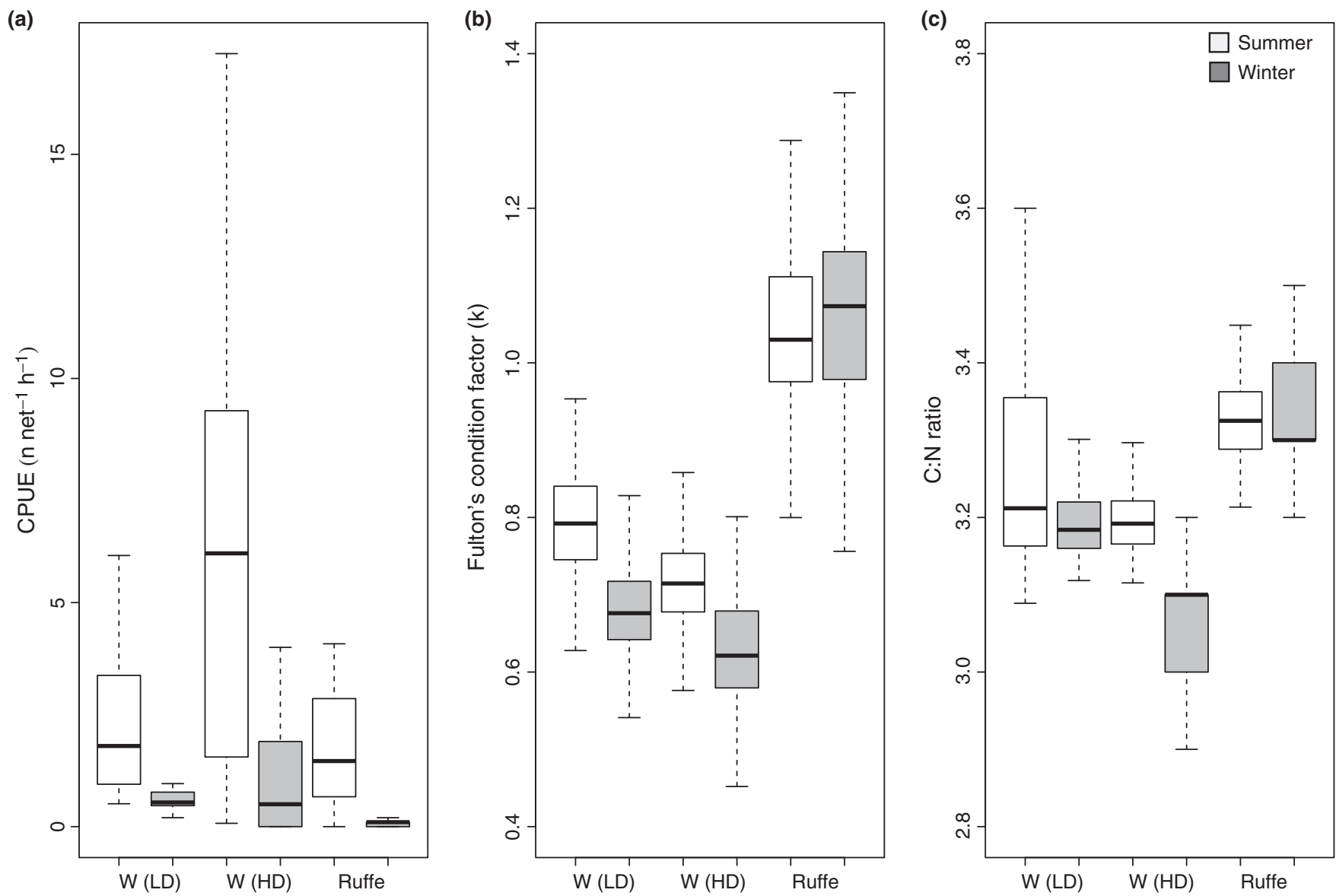

Fig. 7 Seasonal variation in (a) catch-per-unit-effort (CPUE), (b) condition factor and (c) elemental C : N ratio of whitefish in low-density, W (LD), and high-density, W (HD), lakes and ruffe. Bold horizontal lines indicate the median, bars represent upper and lower quartiles, and whiskers represent 1.5 times the quartile range or the maximum/minimum value.

overlap. In all cases, $\delta^{13} \mathrm{C}$ values were comparable between the species (Fig. 5a), whereas ruffe were ${ }^{15} \mathrm{~N}$ enriched relative to whitefish (Fig. 5b). The SIAR mixing model indicated that the contribution of profundal prey to ruffe (95\% credibility limits: $28-76)$ exceeded whitefish (5-46) in all summer samples and in the winter sample from L. Ropi; no discernable variation between the species was evident in the winter samples from L. Kivi or L. Oiko (Fig. 6c, Table S7).

Catch-per-unit-effort of ruffe was significantly reduced in winter relative to summer (Welch $t$-test: $t=3.7$, d.f. $=32.5 P<0.01$; Table 3, Fig. 7a). Mean \pm SD summer CPUE values were $0.9 \pm 0.4 n$ net series ${ }^{-1} \mathrm{~h}^{-1}$ in $\mathrm{L}$. Ropi, $2.2 \pm 1.9 n$ net series ${ }^{-1} \mathrm{~h}^{-1}$ in L. Kivi and $2.2 \pm 0.9 n$ net series ${ }^{-1} \mathrm{~h}^{-1}$ in L. Oiko, whereas mean winter values were $0.1 \pm 0.1-0.2 n$ net series ${ }^{-1} \mathrm{~h}^{-1}$ in all lakes (Fig. 7a). When assessed across lakes, seasonal variation in condition (Fig. $7 \mathrm{~b}$ ) and $\mathrm{C}: \mathrm{N}$ ratio (Fig. 7c) of ruffe was minimal. Length-at-age of ruffe was considerably lower than that of whitefish (Fig. 2d). Mean con- dition factor of ruffe decreased from summer to winter in L. Ropi and L. Kivi, but increased in L. Oiko (Tables 3 \& S2). Mean C : N ratio increased from summer to winter in L. Ropi and L. Oiko and decreased in L. Kivi (Tables 3 \& S2).

The summer diet of other invertebrate consumer fish species in the study lakes was dominated by non-chironomid insects $(32 \pm 40 \%)$, and chironomid larvae were notably absent from the summer diet of such fishes in both LD $(0 \pm 2 \%)$ and HD (0\%) lakes. In winter, chironomid larvae were consumed by other fishes in greater abundance $(18 \pm 32 \%)$, but did not dominate the diet. These data are presented in Table S9, but the low abundance and patchy distribution of these species precludes any statistical analysis.

\section{Discussion}

In subarctic regions, the harsh winter represents a barrier restricting the range of 'cool-adapted' species and 
limiting population density in Europe's northernmost freshwater ecosystems. Recent climate change has diminished the severity of this barrier, while also stimulating increased summer productivity (IPCC, 2013). This has resulted in higher consumer density and diversity across subarctic regions. Despite these trends being well established (Comte et al., 2013), the ecological interactions upon which they are based remain poorly understood. To better elucidate these issues, we examined the effect of recent encroaching species, ruffe, on a dominant resident fish, the whitefish in oligotrophic European subarctic lakes both in summer and in winter.

Our results show a clear effect of consumer density on both the invertebrate and fish communities in the study lakes. Increased consumer density resulted in a seasonal depletion of the benthic prey resources required to maintain consumer fishes during the winter when pelagic productivity is limited. Associated with this depletion in prey resources was a decrease in the growth, condition and lipid reserves of whitefish in high-density relative to low-density communities. This trend was exacerbated when examined across seasons, the seasonal decrease in elemental $\mathrm{C}: \mathrm{N}$ ratio of muscle tissue, a proxy for lipid reserves, in high-density lakes exceeded that of low-density lakes. In contrast to resident whitefish, the small populations of ruffe present in each HD lake displayed minimal seasonal variation in resource use, condition or lipid reserves, emphasising their potential to further expand their range northwards in coming decades.

Our first hypothesis concerned the effect of consumer density on seasonal variation in the diet and condition of whitefish. In the Arctic, strong seasonality often results in a high diversity and abundance of prey in summer and resource limitation in winter, which is reflected in prey selection in both terrestrial and aquatic consumers (Killengreen et al., 2011; Giroux et al., 2012; Hayden et al., 2014a). Whitefish mirrored this trend, exhibiting a pronounced seasonal variation in diet, shifting from a generalist strategy in summer to benthivory in winter. In the absence of a significant density of competitors in LD lakes, whitefish fed almost exclusively on chironomid larvae in winter and exhibited minimal reduction in stomach fullness, condition and lipid reserves between seasons. In HD lakes, however, prey was less abundant; for example, the summer density of pelagic zooplankton in HD lakes was a fraction of that observed in LD lakes. Zooplankton are an important resource to the annual development of fish in subarctic lakes, and their reduced abundance may limit the ability of whitefish in HD lakes to build up lipid reserves dur- ing the summer months (Eloranta et al., 2013; Hayden et al., 2014a). In winter, whitefish in HD lakes diversified their diet to overcome a depletion in chironomid larvae. Commensurate with this dietary shift was a pronounced decrease in the condition of whitefish in HD lakes. Seasonal comparisons of condition may be biased by the effect of spawning, typically in late December, on the mass of whitefish (Hayden et al., 2014a). However, we observed a consistent pattern of lower summer and winter condition of whitefish in HD than in LD lakes. The $\mathrm{C}: \mathrm{N}$ ratios of whitefish provide support for a reduction in body condition (here estimated through a proxy for lipid concentration). Overall, the winter $\mathrm{C}: \mathrm{N}$ ratio of whitefish was lower in HD lakes than LD in lakes, while whitefish $\mathrm{C}: \mathrm{N}$ ratio dropped significantly between summer and winter in all HD lakes and slightly in LD lakes (the anomalous values for L. Siilas excepted).

These factors all point towards the existence of competition for limited prey resources in HD lakes. This competition is either amongst whitefish or via competitive exclusion of whitefish from winter resources by invasive ruffe. Even in the most abundant system, ruffe did not exceed $8 \%$ of total fish biomass, an implausibly low abundance to cause resource exclusion of a dominant species, which itself comprised $50-90 \%$ of fish biomass. Earlier studies of whitefish in the region have indicated relatively high diet overlap between the adjacent age and size classes, highlighting resource competition in dense populations as a cause for decreasing growth in the species (Amundsen et al., 2002; Kahilainen, Lehtonen \& Könönen, 2003; Kahilainen et al., 2005). Although whitefish biomass was broadly similar between HD and LD, the whitefish community in HD lakes consisted of an abundance of small fish, whereas the community of LD lakes contained fewer, larger individuals. Thus, the decrease in whitefish condition and the availability of prey is most likely a consequence of intraspecific competition amongst abundant small whitefish rather than interspecific competition with ruffe. The reduced growth rate of whitefish in the invaded lakes further indicates that the variation in condition and diet represents an obvious consequence of a dense population exhibiting stunted growth.

The second hypothesis examined seasonal variation in the diet and condition of ruffe. Ruffe is an invasive species in many European and North American lakes (Adams \& Maitland, 1998; Ricciardi \& Rasmussen, 1998). Invasive species are often opportunistic generalists that can adapt to new environments (Lockwood, Hoopes \& Marchetti, 2013). However, ruffe's ability to specialise on certain prey appeared to underlie its suc- 
cess. Within its native range, ruffe is a specialist benthivore with a diet typically dominated by chironomid larvae and molluscs (Ogle, 1998). In the study lakes, ruffe fed predominantly on benthic crustaceans in summer and chironomid larvae in winter. This seasonal variation in diet was less evident in its stable isotope ratios. Only in L. Oiko was seasonal variation evident in the resource use of ruffe, as defined by the SIAR mixing model. As variation in the actual isotope ratios of the ruffe in $\mathrm{L}$. Oiko was minimal, this was likely a consequence of increased ZPL in ruffe stomach content in winter, which was entered as a prior in the mixing model.

Winter mortality is a significant limit to the range expansion of warm-adapted invertebrate (Jepsen et al., 2008; Bykova \& Sage, 2012) and vertebrate species (Killengreen et al., 2011; Kauhala \& Ihalainen, 2014). Thus, we expected to see lower activity, stomach fullness and condition in ruffe during winter. Although activity levels were reduced in winter relative to summer, ruffe were captured from all lakes and their stomach fullness indicated that they were actively feeding. Further evidence of the success of ruffe in these lakes was in the robustness of their condition and $\mathrm{C}: \mathrm{N}$ ratios, neither of which exhibited a seasonal drop across the study. As ruffe spawn in early summer, estimates of Fulton's condition index may be influenced by gonad development during the winter; however, as $\mathrm{C}: \mathrm{N}$ ratios were also consistent, it appears likely that ruffe were feeding throughout the year. We did not sample young-of-theyear fish, the most sensitive age group for starvation and mortality (Hurst, 2007); however, our data indicate that $1+$ and older fish, the entire spawning stock, are capable of maintaining an effective population throughout the year at the extreme northern limit of its distribution, despite the presence of a cold-water-adapted native competitor.

It is interesting to note that small ruffe populations located at the extreme northern limit of the species' distribution are capable of obtaining their preferred prey, while maintaining condition and lipid reserves within this competitive environment. The enriched ${ }^{15} \mathrm{~N}$ values reported for ruffe may be telling in this regard. These values mirror those reported in previous investigations in the region and indicate increased predation on profundal resources relative to whitefish in both seasons (Hayden et al., 2013b). This is supported by results of the isotope mixing model, which revealed that ruffe derived more energy from profundal prey than did whitefish. The sampling methods employed in this study preclude a robust comparison of littoral and profundal fish communities; however, it appears that ruffe utilise profundal prey during both seasons, limiting resource competition with abundant whitefish and thereby maintaining condition throughout the winter. It is intriguing that whitefish do not follow suit and shift to profundal prey in winter (Hayden et al., 2014a). Profundal prey densities in these lakes are considerably lower than those of littoral, and as ruffe are a superior benthivore to whitefish, it may be that the resource is not sufficient to sustain both species. Ruffe exhibit morphological adaptations to benthivorous feeding, most notably adaptations of the eye and lateral line which enhance vision and feeding in dark water zones (Hölker \& Thiel, 1998). As increased foraging in the profundal zone by whitefish was not evident in non-invaded lakes, it appears unlikely that there is a strong competitive interaction between the species for profundal resources. As such, at this early stage of invasion ruffe may be able to exploit a vacant profundal niche in these lakes facilitating range expansion without greatly impacting resident whitefish. Such characteristics have been hypothesised for the range expansion previously (Hayden et al., 2013b) and are commensurate with the prediction of increased biodiversity following climate change in subarctic regions. In a study of predicted mammal distribution in Scandinavia, Hof, Jansson \& Nilsson (2012) suggested that while climate change in the region would make it habitable to a greater variety of species only in extreme cases would this lead to the extirpation of resident taxa. It should also be noted that in mesotrophic lakes in the lower part of watercourse, the relative density of ruffe is much higher than that of whitefish (B. Hayden, unpubl. data). This suggests that over a longer timescale further increase in temperature and productivity will likely affect the trophic interactions between ruffe and whitefish favouring the warmer adapted species.

An alternative hypothesis is that ruffe ${ }^{15} \mathrm{~N}$ values resulted in part from predation on fish eggs. Egg predation is a characteristic of ruffe populations throughout their distribution (Ogle, 1998). Predation on fish eggs would explain not only the elevated $\delta^{15} \mathrm{~N}$ values, but also the maintenance of condition and lipid reserves through the winter by ruffe as the species had access to an additional high-value prey item during the winter. Further studies involving seasonal sampling of lacustrine subhabitats or competition experiments between the species, under varied temperature and light regimes (Helland et al., 2011), would be beneficial when attempting to disentangle this scenario.

Variation in fish community structure should also be considered when evaluating putative competition within 
the fish communities. In L. Kivi, the abundance of perch was such to reduce the proportional dominance of whitefish. However, SCA revealed that the majority of these perch were piscivorous. In winter, no small perch were captured indicating that this species was less active than either whitefish or ruffe further limiting their potential impacts on food resources. In L. Ropi, DR whitefish, a specialist plankton feeding morph, may limit the ability of LSR whitefish to successfully forage on zooplankton during summer months (Hayden et al., 2014b). However, in winter when zooplankton abundance fell, only $17 \%$ of DR whitefish captured had food on their stomach, with molluscs rather than chironomid larvae as the dominant prey item.

Ruffe are currently expanding their range northwards, replicating an apparent response to climate change evident across many aquatic and terrestrial species (Parmesan, 2006). Previous investigations have suggested that the presence of ruffe may be deleterious for resident taxa (Hayden et al., 2013b). However, our data indicate that the outcome of inter and intraspecific trophic interactions within these lakes is predominantly driven by resource availability, further complicating any predictions regarding the effects of climate change on this narrow geographic scale. Most climate models suggest that subarctic Europe will warm by $1-2{ }^{\circ} \mathrm{C}$ in the next century, a warming which will result in a shortened winter period and increased productivity in the region's freshwater ecosystems (IPCC, 2013). This will likely lead to an increase in resource availability, which may in turn mediate the impact of additional competitors (e.g. ruffe and potentially cyprinids) on resident fishes following climate-related range expansions.

Our findings build on an increasing data set concerning the effects of seasonal variation in temperature and productivity on the fish energy sources of subarctic lakes (Amundsen \& Knudsen, 2009; Eloranta, Kahilainen \& Jones, 2010; Shuter et al., 2012). Given these recent advances, we support the contention of colleagues that it is vitally important to characterise the trophic ecology of fishes and the ecosystems which maintain them in winter, rather than purely rely on data collected during the summer months. The degree of seasonal variation in the subarctic exceeds that found in most other regions on our planet. Previous studies have shown that generalist native fishes will alter their trophic ecology from summer planktivores to winter benthivores in order to exploit this natural variation in prey abundance (Hayden et al., 2014a). While this strategy may appear in synchrony with the annual fluctuation in resource availability, the data presented here show that resource competition, whether inter- or intraspecific in nature, is intensified in winter resulting in depletion of resources and obvious deleterious effects on resident fishes.

\section{Acknowledgments}

The authors wish to thank Kilpisjärvi Biological Station, G. Hayden, T. Holopainen, O. Kalttopää, J-P. Myllykangas, P. Nieminen, O. Saari and M. Sujala. Financial support was provided from Fisheries Society of British Isles, Academy of Finland (projects 140903, 1268566), Emil Aaltonen Foundation and European Regional Developmental Fund (project A30205). We are grateful to two anonymous reviewers and the subject editor whose suggestions significantly enhanced this manuscript.

\section{References}

Adams C.E. \& Maitland P.S. (1998) The ruffe population of Loch Lomond, Scotland: its introduction, population expansion, and interaction with native species. Journal of Great Lakes Research, 24, 249-262.

Amundsen P.-A. \& Knudsen R. (2009) Winter ecology of Arctic charr (Salvelinus alpinus) and brown trout (Salmo trutta) in a subarctic lake, Norway. Aquatic Ecology, 43, 765-775.

Amundsen P.-A., Kristoffersen R., Knudsen R. \& Klemetsen A. (2002) Long-term effects of a stock depletion programme: the rise and fall of a rehabilitated whitefish population. In: Advances in Limnology 57: Biology and Management of Coregonid Fishes - 1999. Ergebnisse Der Limnologie (Eds T. Todd \& G. Fleischer), pp. 577-588. E Schweizerbart'sche Verlagsbuchhandlung, Stuttgart.

Araújo M.B. \& Peterson A.T. (2012) Uses and misuses of bioclimatic envelope modeling. Ecology, 93, 1527-1539.

Bagenal T.B. \& Tesch F.W. (1978) Age and growth. In: Methods for Assessment of Fish Production in Fresh Waters, 3rd edn (Ed. T.B. Bagenal), pp. 101-136. Blackwell Scientific Publications Ltd, London.

Brown J.H., Gillooly J.F., Allen A.P., Savage V.M. \& West G.B. (2004) Toward a metabolic theory of ecology. Ecology, 85, 1771-1789.

Bykova O. \& Sage R.F. (2012) Winter cold tolerance and the geographic range separation of Bromus tectorum and Bromus rubens, two severe invasive species in North America. Global Change Biology, 18, 3654-3663.

Carmel Y., Kent R., Bar-Massada A., Blank L., Liberzon J., Nezer O. et al. (2013) Trends in ecological research during the last three decades - a systematic review. PLOS ONE, 8, e59813.

Comte L., Buisson L., Daufresne M. \& Grenouillet G. (2013) Climate-induced changes in the distribution of freshwater fish: observed and predicted trends. Freshwater Biology, 58, 625-639. 
Eloranta A.P., Kahilainen K.K. \& Jones R.L. (2010) Seasonal and ontogenetic shifts in the diet of Arctic charr Salvelinus alpinus in a subarctic lake. Journal of Fish Biology, 77, 80-97.

Eloranta A.P., Mariash H.L., Rautio M. \& Power M. (2013) Lipid-rich zooplankton subsidise the winter diet of benthivorous Arctic charr (Salvelinus alpinus) in a subarctic lake. Freshwater Biology, 58, 2541-2554.

Fukami T. \& Wardle D. (2005) Long-term ecological dynamics: reciprocal insights from natural and anthropogenic gradients. Proceedings of the Royal Society of London B: Biological Sciences, 272, 2105-2115.

Giroux M.-A., Berteaux D., Lecomte N., Gauthier G., Szor G. \& Bêty J. (2012) Benefiting from a migratory prey: spatio-temporal patterns in allochthonous subsidization of an Arctic predator. Journal of Animal Ecology, 81, 533-542.

Harrod C., Mallela J. \& Kahilainen K.K. (2010) Phenotypeenvironment correlations in a putative whitefish adaptive radiation. Journal of Animal Ecology, 79, 1057-1068.

Hayden B., Harrod C. \& Kahilainen K.K. (2013a) The effects of winter ice cover on the trophic ecology of whitefish (Coregonus lavaretus L.) in subarctic lakes. Ecology of Freshwater Fish, 22, 192-201.

Hayden B., Harrod C. \& Kahilainen K.K. (2014a) Dual fuels: intra-annual variation in the relative importance of benthic and pelagic resources to maintenance, growth and reproduction in a generalist salmonid fish. Journal of Animal Ecology, 83, 1501-1512.

Hayden B., Harrod C. \& Kahilainen K.K. (2014b) Lake morphometry and resource polymorphism determine niche segregation between cool- and cold-water adapted fish. Ecology, 95, 538-552.

Hayden B., Holopainen T., Amundsen P.-A., Eloranta A.P., Knudsen R., Præbel K. et al. (2013b) Interactions between invading benthivorous fish and native whitefish in subarctic lakes. Freshwater Biology, 58, 1234-1250.

Hays G.C., Richardson A.J. \& Robinson C. (2005) Climate change and marine plankton. Trends in Ecology $\mathcal{E}$ Evolution, 20, 337-344.

Helland I.P., Finstad A.G., Forseth T., Hesthagen T. \& Ugedal O. (2011) Ice-cover effects on competitive interactions between two fish species. Journal of Animal Ecology, 80, 539-547.

Hof A.R., Jansson R. \& Nilsson C. (2012) Future climate change will favour non-specialist mammals in the (sub) arctics. PLOS ONE, 7, e52574.

Hölker F. \& Thiel R. (1998) Biology of ruffe (Gymnocephalus cernuus (L.)) - a review of selected aspects from European literature. Journal of Great Lakes Research, 24, 186-204.

Hurst T.P. (2007) Causes and consequences of winter mortality in fishes. Journal of Fish Biology, 71, 315-345.

IPCC (2013) IPCC Fifth Assessment Report Climate Change 2013: the physical science basis summary for policymakers. Cambridge University Press, Cambridge, United Kingdom and New York, NY, USA.
Jackson A.L., Inger R., Parnell A.C. \& Bearhop S. (2011) Comparing isotopic niche widths among and within communities: SIBER - Stable Isotope Bayesian Ellipses in $\mathrm{R}$. Journal of Animal Ecology, 80, 595-602.

Jepsen J., Hagen S., Ims R. \& Yoccoz N. (2008) Climate change and outbreaks of the geometrids Operophtera brumata and Epirrita autumnata in subarctic birch forest: evidence of a recent outbreak range expansion. Journal of Animal Ecology, 77, 257-264.

Kahilainen K., Lehtonen H. \& Könönen K. (2003) Consequence of habitat segregation to growth rate of two sparsely rakered whitefish (Coregonus lavaretus (L.)) forms in a subarctic lake. Ecology of Freshwater Fish, 12, 275-285.

Kahilainen K.K., Alajärvi E. \& Lehtonen H. (2005) Planktivory and diet-overlap of densely rakered whitefish (Coregonus lavaretus (L.)) in a subarctic lake. Ecology of Freshwater Fish, 14, 50-58.

Kahilainen K.K. \& Lehtonen H. (2003) Piscivory and prey selection of four predator species in a whitefish dominated subarctic lake. Journal of Fish Biology, 63, 659-672.

Kahilainen K.K., Malinen T., Tuomaala A., Alajärvi E., Tolonen A. \& Lehtonen H. (2007) Empirical evaluation of phenotype-environment correlation and trait utility with allopatric and sympatric whitefish, Coregonus lavaretus (L.), populations in subarctic lakes. Biological Journal of the Linnean Society, 92, 561-572.

Kauhala K. \& Ihalainen A. (2014) Impact of landscape and habitat diversity on the diversity of diets of two omnivorous carnivores. Acta Theriologica, 59, 1-12.

Kiljunen M., Grey J., Sinisalo T., Harrod C., Immonen H. \& Jones R.I. (2006) A revised model for lipid-normalizing $\delta 13 \mathrm{C}$ values from aquatic organisms, with implications for isotope mixing models. Journal of Applied Ecology, 43, 1213-1222.

Killengreen S.T., Lecomte N., Ehrich D., Schott T., Yoccoz N.G. \& Ims R.A. (2011) The importance of marine vs. human-induced subsidies in the maintenance of an expanding mesocarnivore in the Arctic tundra. Journal of Animal Ecology, 80, 1049-1060.

Levins R. (1968) Evolution in Changing Environments: Some Theoretical Explorations. Princeton University Press, Princeton, NJ.

Lockwood J.L., Hoopes M.F. \& Marchetti M.P. (2013) Invasion Ecology. Wiley-Blackwell, Oxford.

Lowry E., Rollinson E.J., Laybourn A.J., Scott T.E., AielloLammens M.E., Gray S.M. et al. (2013) Biological invasions: a field synopsis, systematic review, and database of the literature. Ecology and Evolution, 3, 182-196.

McArdle B.H. \& Anderson M.J. (2001) Fitting multivariate models to community data: A comment on distancebased redundancy analysis. Ecology, 82, 290-297.

McCutchan J.H., Lewis W.M., Kendall C. \& McGrath C.C. (2003) Variation in trophic shift for stable isotope ratios of carbon, nitrogen, and sulfur. Oikos, 102, 378-390.

(C) 2015 John Wiley \& Sons Ltd, Freshwater Biology, 60, 1000-1015 
Ogle D.H. (1998) A synopsis of the biology and life history of ruffe. Journal of Great Lakes Research, 24, 170-185.

Parmesan C. (2006) Ecological and evolutionary responses to recent climate change. Annual Review of Ecology, Evolution, and Systematics, 37, 637-669.

Parnell A.C., Inger R., Bearhop S. \& Jackson A.L. (2010) Source partitioning using stable isotopes: coping with too much variation. PLOS ONE, 5, e9672.

R Core Team (2014) R: A Language and Environment for Statistical Computing. R Foundation for Statistical Computing, Vienna, Austria.

Rahel F. \& Olden J. (2008) Assessing the effects of climate change on aquatic invasive species. Conservation Biology, 22, 521-533.

Rautio M., Dufresne F., Laurion I., Bonilla S., Vincent W.F. \& Christoffersen K.S. (2011) Shallow freshwater ecosystems of the circumpolar Arctic. Ecoscience, 18, 204-222.

Ricciardi A. \& Rasmussen J.B. (1998) Predicting the identity and impact of future biological invaders: a priority for aquatic resource management. Canadian Journal of Fisheries and Aquatic Sciences, 55, 1759-1765.

Shuter B.J., Finstad A.G., Helland I.P., Zweimüller I. \& Hölker F. (2012) The role of winter phenology in shaping the ecology of freshwater fish and their sensitivities to climate change. Aquatic Sciences, 74, 637-657.

Sorvari S., Korhola A. \& Thompson R. (2002) Lake diatom response to recent Arctic warming in Finnish Lapland. Global Change Biology, 8, 171-181.

Swynnerton G.H. \& Worthington E.B. (1940) Note on the Food of Fish in Haweswater (Westmorland). Journal of Animal Ecology, 9, 183-187.

Tylianakis J., Didham R., Bascompte J. \& Wardle D. (2008) Global change and species interactions in terrestrial ecosystems. Ecology letters, 11, 1351-1363.

\section{Supporting Information}

Additional Supporting Information may be found in the online version of this article:

Table S1. Mean $( \pm S D)$ stable isotope values of littoral (BMI-Litt) and profundal (BMI-Prof) benthic macroinvertebrates as well as pelagic zooplankton (ZPL), baseline values for the SIAR mixing model are presented in bold. Table S2. Mean $( \pm S D)$ catch per unit effort (CPUE), biomass per unit effort (BPUE), Fulton's condition factor $(k)$ and elemental $\mathrm{C}: \mathrm{N}$ ratio of muscle tissue of whitefish and ruffe from the study sites.

Table S3. Mean $( \pm S D)$ length-at-age of whitefish and ruffe recorded from the six study lakes.

Table S4. Mean $( \pm \mathrm{SD})$ density $\left(n \mathrm{~m}^{-2}\right)$ of benthic macroinvertebrate groups recorded from littoral $(1 \mathrm{~m})$ and profundal $(>5 \mathrm{~m})$ zones in each lake.

Table S5. Mean $( \pm \mathrm{SD})$ density of zooplankton $\left(n \mathrm{~L}^{-1}\right)$ recorded from vertical tows in each lake.

Table S6. Mean $( \pm S D)$ proportion of the main prey groups in the diet of whitefish and ruffe sampled from each lake.

Table S7. Sample size $(n)$, mean $( \pm \mathrm{SD})$ stable isotope values of whitefish and ruffe from each lake in summer and winter.

Table S8. Inter-specific trophic interactions between whitefish and ruffe.

Table S9. Mean $( \pm S D)$ stomach content of other consumer fishes in the study lakes.

(Manuscript accepted 16 February 2015) 